\title{
Comunicação em Saúde: Experiências da Rádio Web Saúde com jovens latino-americanos ${ }^{1}$
}

\section{Health Communication: Experiences of Health Web Radio with young Latin Americans}

\author{
Dra. Ana Valéria MACHADO MENDONÇA \\ Universidad de Brasília (Brasil) \\ valeriamendonca@gmail.com \\ Dra. Maria Fátima DE SOUSA \\ Universidad de Brasília (Brasil) \\ mariafatimasousa@gmail.com \\ Grasiela DE SOUSA PEREIRA \\ Universidad de Brasília (Brasil) \\ grasi.saude@gmail.com \\ Dyego RAMOS HENRIQUE \\ Universidad de Brasília (Brasil) \\ dyegoramosunb@gmail.com
}

Raelma PAZ SILVA

Universidad de Brasília (Brasil)

raelma.gesco@gmail.com

Weverton Vieira DA SILVA ROSA

Universidad de Brasília (Brasil)

velber35@gmail.com

Recibido: 10 de septiembre 2013

Aceptado y Publicado: 4 de noviembre de 2013

\footnotetext{
${ }^{1}$ Artículo producto de una Ponencia presentada en el VI Encuentro Panamericano de Comunicación COM PANAM 2013 celebrado la Escuela de Ciencias de la Información de la Universidad Nacional de Córdoba (Argentina), durante los días 5, 6 y 7 de junio de 2013.
} 


\section{Resumo}

O presente trabalho visa divulgar os resultados obtidos em oficina realizada no I Seminário Latino-americano sobre Juventude, Saúde Pública e Participação Social, realizado de 21 a 24 de novembro de 2012, em Brasília, moderada pela equipe do Projeto Radio Web Saúde da Universidade de Brasília. Tendo como tema a "participação juvenil", a referida oficina serviu para subsidiar a elaboração de Carta de Intenções da Juventude da América Latina em Saúde Pública, onde se espelham as expectativas dos jovens acerca da participação política por eles almejada e raras vezes contemplada nas políticas públicas do continente. $O$ Seminário contou com a participação de cerca de 350 jovens de 16 países da América Latina, integrantes do Movimento Jovem de Políticas Públicas, com idades variando entre 12 e 21 anos. A Rádio Web Saúde é um projeto idealizado e realizado por estudantes de graduação em Saúde Coletiva da Universidade de Brasília, com base em estratégias de comunicação em saúde subsidiadas por novas tecnologias de informação e comunicação.

\section{Abstract}

This paper aims to disseminate the results obtained in the workshop held at the First Latin American Seminar on Youth, Public Health and Social Participation, held from 21 to 24 November 2012 in Brasilia, moderated by the Radio Web Design Health, University staff Brasilia. On the subject of "youth participation", said the workshop served to support the development of Lol Youth Latin American Public Health where they mirror the expectations of youth about the political participation desired by them and rarely contemplated policies public of the continent. The Seminar was attended by about 350 young people from 16 Latin American countries, members of the Youth Movement of Public Policy, with ages ranging between 12 and 21 years. The Web is an idealized Radio Health and conducted by graduate students in Public Health at the University of Brasilia project, based on communication strategies in health care subsidized by new information technologies and communication. 
Palavras-chave: juventude, participação juvenil, direito, políticas públicas

Key Words: youth, youth participation, law, public policy.

\section{Introdução}

Brasília sediou nos dias 21 a 23 de novembro de 2012 o I Seminário Latino- americano sobre Juventude, Saúde Pública e Participação Social. Este evento foi promovido pelo Ministério da Saúde, com o apoio do Departamento de Ouvidoria Geral do Sistema Único de Saúde (DOGES), Ao longo do evento, os presentes foram agrupados em oficinas cujos temas eram "determinantes sociais da saúde", "participação juvenil" e "direito universal à saúde". Para estimular a fala de todos os presentes, foi adotada a modalidade "roda de conversa". As conclusões de cada oficina subsidiaram a elaboração de uma Carta de Intenções sobre a Participação das Juventudes da América Latina em Saúde Pública aprovada em uma Plenária no último dia dos trabalhos.

$\mathrm{Na}$ ocasião, os jovens tiveram oportunidade de apresentar algumas de suas inquietações sobre a temática. A frase mais ouvida durante o seminário foi: como "a juventude na América Latina precisa ter ciência dos seus direitos". Nas oficinas promovidas para a elaboração da Carta de Intenções os jovens reivindicaram o direito de atuar nos espaços onde ocorre a formulação de políticas públicas em seus países de origem.

A percepção da necessidade de uma atenção diferenciada para os jovens só começou a surgir na década de 1980, impulsionada pelo processo de redemocratização do Brasil e pela mobilização em torno dos direitos da criança e do adolescente, que gerou a inclusão do art. 227 da Constituição Federal e a elaboração do Estatuto da Criança e do Adolescente (ECA), que abarca os "jovens-adolescentes", cuja faixa se estende dos 15 aos 17 anos. Esse debate é ampliado quando a Organização das Nações Unidas (ONU) institui 1985 como o Ano Internacional da Juventude - Participação, Desenvolvimento e Paz, que torna mais evidente o tema nos Estados-membros mas 
que, pelo menos no Brasil, ainda não causa impactos na estruturação de políticas com este foco. O estímulo só vem dez anos depois, quando a ONU, através da elaboração e aprovação do Programa Mundial de Ação para a Juventude (PMAJ), convoca os países-membros a pensarem estratégias para o presente e o futuro dos jovens e a elaborarem uma Política Nacional de Juventude. (BRASIL, 2010, p. 04)

Segundo CARVALHO (2006, p. 171) "colocar a temática da juventude na pauta das agendas governamentais e na representação dos gastos públicos, não subentende uma política pública de juventude que se efetiva no plano da práxis".

Vale lembrar que o processo harmônico de interação entre Estado e sociedade civil, inclusive os meios de comunicação, é fator que contribui para a solidificação da "cultura" de políticas públicas integrais para os jovens brasileiros. Além disso, a juventude é pouco vista sobre a ótica dos conflitos geracionais que refletem o plano subjetivo no momento da construção da identidade juvenil. Estes conflitos, também, estão interligados a uma violência invisível, oriunda dos limites do jogo político. Da invisibilidade ao visível, advém a necessidade da compreensão da condição juvenil contemporânea, compreensão que deve ser transposta aos gestores e executores das políticas sociais. (CARVALHO, 2006, p. 172)

O objetivo deste relato é descrever a experiência dos estudantes de Saúde Coletiva da Universidade de Brasília, integrantes do Projeto Rádio Web Saúde- UnB/Brasil, na mediação das conversas, empoderando esses jovens, e buscando democratizar suas formas de participação coletiva.

O projeto Rádio Web Saúde destina-se aos profissionais de saúde, gestores, conselheiros de saúde, professores, estudantes, comunidades das Secretarias Estaduais e Municipais de Saúde no Brasil e à comunidade latino-americana. Criada em 2011, a iniciativa visa produzir conteúdos e avaliar os processos de comunicação em saúde a fim de contribuir com a inclusão social dos cidadãos junto às ações do Sistema Único de Saúde (SUS), que hoje 
conta com o apoio estratégico de Instituição de Ensino Superior, Grupos de Pesquisa, Conselhos Nacionais e do Ministério da Saúde no Brasil.

Como estratégia de comunicação moderada por tecnologias, a proposta tem se apresentado como mediadora dos processos comunicacionais a partir do modelo teórico metodológico de Muitos para Muitos, tendo a web como canal de comunicação dialógico para estimular a produção de conteúdos, gestão da informação e disseminação do conhecimento e a análise crítica dos produtos e linguagens, oferecendo múltiplas leituras para os conteúdos disponibilizados em ambiente web desenvolvido a partir de software livre e produzidos em imagens estáticas, áudio e vídeo transcritos em texto, e com imagens traduzidas em Libras para os deficientes auditivos.

\section{Metodologia}

O seminário contou com a participação de cerca de 350 jovens, representando 16 países da América Latina, e outros representantes de governo e estudantes universitários, que puderam participar das discussões via web, graças à atuação da equipe da Rádio Web Saúde, que transmitiu o evento em tempo real democratizando desta forma a participação popular. Os adolescentes e jovens que foram selecionados para participar do seminário e das oficinas fazem parte da Organização Visão Mundial. Nela emprega-se a metodologia de Monitoramento Jovem de Políticas Públicas (MJPOP) de saúde, educação, esporte e lazer. Tais processos têm como facilitadores outros jovens, na sua maioria entre 16 e 24 anos, capacitados para promover processos de empoderamento da comunidade onde vivem, através de reuniões comunitárias, conversas com poder público, dentre outras iniciativas.

Coube à equipe da Radio Web Saúde a moderação de uma oficina com cerca de 40 jovens de ambos os sexos com idades variando entre 12 e 21 anos. Em três sessões de discussão e problematização foi abordado o tema da "participação juvenil". 


\section{Resultados}

A oficina em questão foi desenvolvida em torno das perguntas-chave capazes de introduzir a discussão sobre o tema "participação juvenil": "O que é participação juvenil?" "O que facilita e dificulta?" "Como melhorar a participação juvenil na construção de políticas públicas?" "Em que espaços os jovens podem exercer a participação juvenil?" e "O que os motiva a participar?".

Nas falas dos jovens predominou a ideia de que a democracia precisa ser exercida como direito de todos e que os direitos precisam ser respeitados. A palavra "protagonismo" apareceu repetidas vezes ligada ao exercício da liberdade. A sociedade é vista como o ente que discrimina os jovens e age com preconceito. Foi citada a importância de eles se apropriarem dos espaços de construção de políticas públicas para um melhor diálogo na construção de consensos. "Participar" foi associado a "construir" e mencionado como um verbo de ação, que exige "movimentação e luta".

Os jovens que participaram da oficina aquí retratada discutiram o que dificulta a participação juvenil. As respostas relacionaram a dificuldade que os jovens em geral têm de compreender que a participação em si já deve ser entendida como um direito e que alienação das pessoas sobre seus próprios direitos e deveres é um fato corriqueiro.

A ausência de diálogo dos entes do governo com a sociedade e a falta de acesso à educação de qualidade foram vistos como fatores geradores vulnerabilidade. Quando não há igualdade de direitos e predomina a falta de espaços de diálogo e a ausência de comprometimento criam-se as condições favoráveis para a construção de um sistema educacional sem espaço para formação de jovens críticos, protagonistas no exercício do seu direito a participação. 


\subsection{Proposições para melhorar a participação juvenil}

A maioria das intervenções observadas reivindicou o reconhecimento pelo Estado dos jovens como agentes e pessoas de direito, como solução de problemas e não como "um problema". Destacou-se a necessidade de incentivar a realização de conferências e seminários que favoreçam a participação e o protagonismo juvenil, com estímulo à livre expressão juvenil cultural e política.

Os jovens que participaram da referida oficina também ressaltaram o fato de viverem em uma sociedade onde são ensinados a não discordar, não pensar de forma crítica e a estar sempre a mercê de um sistema desestimulante que se ancora na ilusão do consumismo.

Como solução para este estado de coisas, atribuem à educação um papel de importância para a formação de jovens empoderados, participativos e cientes de seus direitos. Neste sentido, sugeriram a revisão dos currículos escolares da formação básica para que haja a inserção de espaços de discussão acerca dos Direitos Humanos nas escolas. Tal iniciativa visaria criar mecanismos de desconstrução de preconceitos de todas as formas e promovería a a formação de cidadãs e cidadãos mais conscientes, em sua opinião

Outro aspecto bastante enfatizado pelo grupo foi a ausência de espaços de participação juvenil nos locais onde se dá a criação das políticas públicas. No que se refere a tomadas de decisão, o jovem não seria consultado sobre políticas pensadas para ele. É necessário ampliar os espaços de participação dos jovens, seja por meio de conselhos ou secretarias da juventude, mas também pela criação de outros fóruns de deliberação e ampla participação dos jovens.

Com o objetivo de ampliar e fortalecer estratégias de interação e comunicação da juventude latino-americana em tempos de revolução digital os jovens propuseram a criação de uma revista eletrônica que pudesse ser um instrumento de mobilização e debate. 
Foi proposta a criação de um estímulo aos países que implantam e incentivam a participação juvenil na forma de um certificado de "País amigo da juventude", a ser concedido pela Organização Pan-americana de Saúde (OPAS) e/ou Organização das Nações Unidas (ONU)

\subsection{Quais são os espaços de participação juvenil?}

Para os jovens ora retratados, todos os lugares são espaços de participação juvenil. Mas para que os jovens tenham essa participação efetiva é importante que tenham primeiramente a informação e a formação necessárias para ocuparem tais ambientes. Com isso, mais uma vez ressalta-se a importância das escolas serem parceiras no sentido de formar cidadãos conscientes e capazes de exercer sua cidadania em todos os espaços.

Ficou evidente que a pouca idade atrapalha o acesso do jovem às esferas do Poder Públicoe organizações privadas. Mas são nesses locais que os jovens devem exercer seu direito de participar, opinar e decidir. Em sua própria comunidade, o jovem pode ser atuante junto aos conselhos locais de discussão e deliberação, nas paróquias e igrejas...

Os jovens latino-americanos querem dizer ao mundo: "Somos uma força de luta e organização; somos sujeitos da construção do hoje e do amanhã; reconhecemos a participação como um direito cidadão; somos sim capazes de construir um futuro melhor, através da participação emancipadora, do diálogo, das ações que modificam a realidade."

\subsection{O que move os jovens?}

Uma jovem boliviana, assim se expressou a este respeito: "O fato de perceber a força que possuem a cada conquista, o desejo de transformar a realidade existente pela utopia de alcançar um mundo possível, para que nesse mundo possível exista saúde como direito para todos, onde os jovens tenham voz e espaço respeitados. Perceber que para que tudo isso aconteça é preciso reconhecer que a construção de um mundo mais justo é responsabilidade 
de todos. "É necessário que se entenda a importância dos direitos humanos como garantia de direitos a todos os seres humanos."

Com esse desejo de transformação os jovens latino-americanos seguem na luta pela conquista de seus direitos; Em muitos casos lutam pela efetivação de direitos conquistados, mas não respeitados.

\section{Considerações Finais}

\subsection{Direito, Protagonismo, Capacidade}

Participar de uma organização que tem como missão discutir políticas públicas com jovens produz uma visão crítica do mundo em que estão inseridos. Ser protagonista da própria história estimula a idéia de agentes que participam e decidem sobre seu futuro. A fala pronunciada com a autoridade de quem vivencia diariamente o preconceito e a falta de atenção qualificada das autoridades revela uma juventude que tem sonhos, que deseja que um dia sua voz seja ouvida e seus direitos de cidadão respeitados.

Abaixo, destacamos um trecho da Carta aprovada ao final do Seminário.

- Demandamos às instituições nacionais e internacionais o reconhecimento das propostas desta Carta. Propomos também a Organização Pan-americana de Saúde (OPAS), ao MERCOSUL-Saúde e à UNASUL-Saúde a criação de um incentivo aos países que implantam, programam e fortalecem os espaços de participação juvenil em saúde promovendo o protagonismo do mesmo, o que neste documento chamamos de certificado de um "País Amigo das Juventudes".

- Por fim, nós jovens nos comprometemos a ser vigilantes do cumprimento das políticas públicas e a fortalecer os espaços de participação social da saúde. 
(Carta de Intenções sobre a Participação das Juventudes da América Latina em Saúde Pública)

\section{Referências Bibliográficas}

BRASIL, Secretaria Geral da Presidência da República- Secretaria Nacional de Juventude. Conselhos de Juventude: Fortalecendo Diálogos, Promovendo Direitos. Brasília, maio, 2010

CARVALHO, G.C.A. Juventude e Políticas Públicas: mero destaque na agenda públicas ou garantia de direitos? Revista Eletrônica dos Pós-Graduandos em Sociologia Pública da UFSC Vol. 2 no 2 (4), agosto-dezembro/2006, p. 163-15

http://culturadigital.br/jovemparticipasaude/files/2013/02/CARTA-Semin\%C3\%A1 rio2.pdf http://www.visaomundial.org.br/conteudos/view/a-visao-mundial.html

\section{Forma de citar este artículo en bibliografías}

MACHADO MENDONÇA, A.; DE SOUSA, M; et al (2013): "Comunicação em Saúde: Experiências da Rádio Web Saúde com jovens latino-americanos", en Revista PANGEA, 4, páginas 279 a 288. Red Académica Iberoamericana de Comunicación. Recuperado el _ de de 2 ___ de: http://revistapangea.org 